\title{
Dermatological Manifestations of Patients with Chronic Kidney Disease on Hemodialysis
}

\author{
Dorchhom K $\mathbf{1}^{1}$, Kumar $\mathrm{A}^{2}$, Bansal N³, Pandey $\mathrm{AN}^{4}$, Mehta $\mathrm{A}^{5}$, Bisth $\mathrm{JS}^{6}$, Varma $\mathrm{A}^{7}$ \\ ${ }^{1}$ Dr Dorchhom Khrime, Associate Professor, Department of Medicine, ${ }^{2}$ Dr Alok Kumar, Incharge Nephrology Unit, \\ Associate Professor, Department of Medicine, ${ }^{3}$ Dr Nitin Bansal, Associate Professor, Department of Medicine, ${ }^{4}$ Dr Amar \\ Nath Pandey, Associate Professor, Department of Medicine, ${ }^{5}$ Dr Anil Mehta, Professor and Head, Department of \\ Dermatology, ${ }^{6}$ Dr Jitendra Singh Bisth, Associate Professor Department of Dermatology, ${ }^{7}$ Dr Amit Verma, Professor and \\ Head, Department of Medicine. All are affiliated with Shri Guru Ram Rai Institute of Medical and Health Sciences Patel \\ Nagar, Dehradun, Uttarakhand, India
}

Address for correspondence: Dr. Alok Kumar, Email: alokkraj@rediffmail.com

\begin{abstract}
Background and Objective: Chronic kidney disease patients on dialysis face various cutaneous problems. Common problems are xerosis, pruritus, pallor, pigmentation changes, hair changes and nail changes. We planned to look for cutaneous alterations in our patients on maintenance dialysis. Material and Methods: We included all patients on maintenance hemodialysis. We recorded their demographic profile and relevant investigations. All patients were examined by department of medicine and findings were confirmed by dermatologist. Specific investigations like skin biopsy, culture and sensitivity for bacterial infections, Gram's stain, potassium hydroxide mount and fungal culture were done where indicated. Results: There was one hundred forty patients. Mean age of patients was 38.7 \pm 7.4 years. Gender ratio was 1.32:1 (male: female). Mean duration of dialysis was 11.7 \pm 5.6 months. All patients had at least one cutaneous manifestation. Thirty four $(24.28 \%)$ patients had two cutaneous manifestations. Twenty one (17.85\%) patients had three or more cutaneous manifestations. Xerosis was seen in $74.8 \%$ patients. Pigmentary changes were seen in $43.57 \%$ patients. Nail changes were seen in fifty seven patients. Half and half nail was seen in twenty six (18.57\%) patients. Hair changes were seen in forty nine $(35 \%)$ patients. Cutaneous infections were seen in forty six patients. Most common infection was dermatophytosis in twenty eight patients (20\%). Conclusion: CKD patients on dialysis suffer with multiple skin problems. Early detection of these problems like xerosis, cutaneous infection, and pruritus might result in improvement in quality of life.
\end{abstract}

Key words: Chronic Kidney Disease, Cutaneous Manifestations, Xerosis, Pruritus, Half and Half nail.

\section{Introduction}

Chronic kidney disease (CKD) is associated with various dermatological manifestations. These could be due to renal insufficiency or due to disease causing chronic kidney disease. Systemic lupus erythematosus or Vasulitis had been described with typical skin rashes. On other hand chronic renal insufficiency can also cause lot of skin manifestations. These have been described in various studies in almost all patients on maintenance hemodialysis. [1].There are different kinds of cutaneous alterations described in CKD like Xerosis, pruritus, pallor, hyperpigmentation, half and half nail, and brittle hair [2]. In this background we took this study to look for cutaneous alterations in patients of CKD on maintenance hemodialysis at our institute.

Manuscript received: $10^{\text {st }}$ Sep 2014

Reviewed: $20^{\text {th }}$ Sep 2014

Author Corrected: $16^{\text {th }}$ Oct 2014

Accepted for Publication: $30^{\text {th }}$ Oct 2014

\section{Material and Methods}

One hundred forty patients of CKD on maintenance haemodialysis from May 2008 to May 2013 at our institute were included. All patients underwent detailed dermatological examination by internist and later confirmed by dermatologist. Their basic demographic profile was noted. We collected data for cause of kidney disease, duration of renal disease, duration of dialysis.

Their haemoglobin, serum urea, serum creatinine, serum calcium, serum phosphorus were also recorded. Adequacy of dialysis was calculated by $\mathrm{kt} / \mathrm{v}$ using Daugirdas formula. Patients on peritoneal dialysis were excluded. Patients of acute renal injury were also excluded. Specific investigations like skin biopsy, culture and sensitivity for bacterial infections, Gram's stain, potassium hydroxide mount and fungal culture were done 
where indicated, after informed consent. Routine investigations for monitoring renal functions were recorded. The severity of xerosis was assessed by a modified version of the grading by Morton [3]: grade 0 (smooth skin), grade 1 (rough skin) and grade 2 (rough skin with scaling).

\section{Results}

There were one hundred forty patients. Mean age of patients was $38.7 \pm 7.4$ years (19 to 73 years). There were eighty seven males and fifty three females. Gender ratio was 1.32:1 (male: female). Mean duration of dialysis was 11.7 \pm 5.6 months. Range for duration of hemodialysis was 2 months to 5 years. Mean Haemoglobin was $9.4 \pm 1.5$ gm \%. Mean blood urea and serum creatinine level were $188 \pm 27.3 \mathrm{mg} \%$ and $8.7 \pm 1.9 \mathrm{mg} \%$. Mean serum calcium and phosphorus level were $8.9 \pm 1.1 \mathrm{mg} \%$ and $6.8 \pm 2.3 \mathrm{mg} \%$.

Mean serum albumin level were $3.2 \pm .3 \mathrm{mg} \%$. Causes of chronic kidney disease have been shown in figure 1 . Mean $\mathrm{kt} / \mathrm{v}$ was $1.16 \pm .03$.

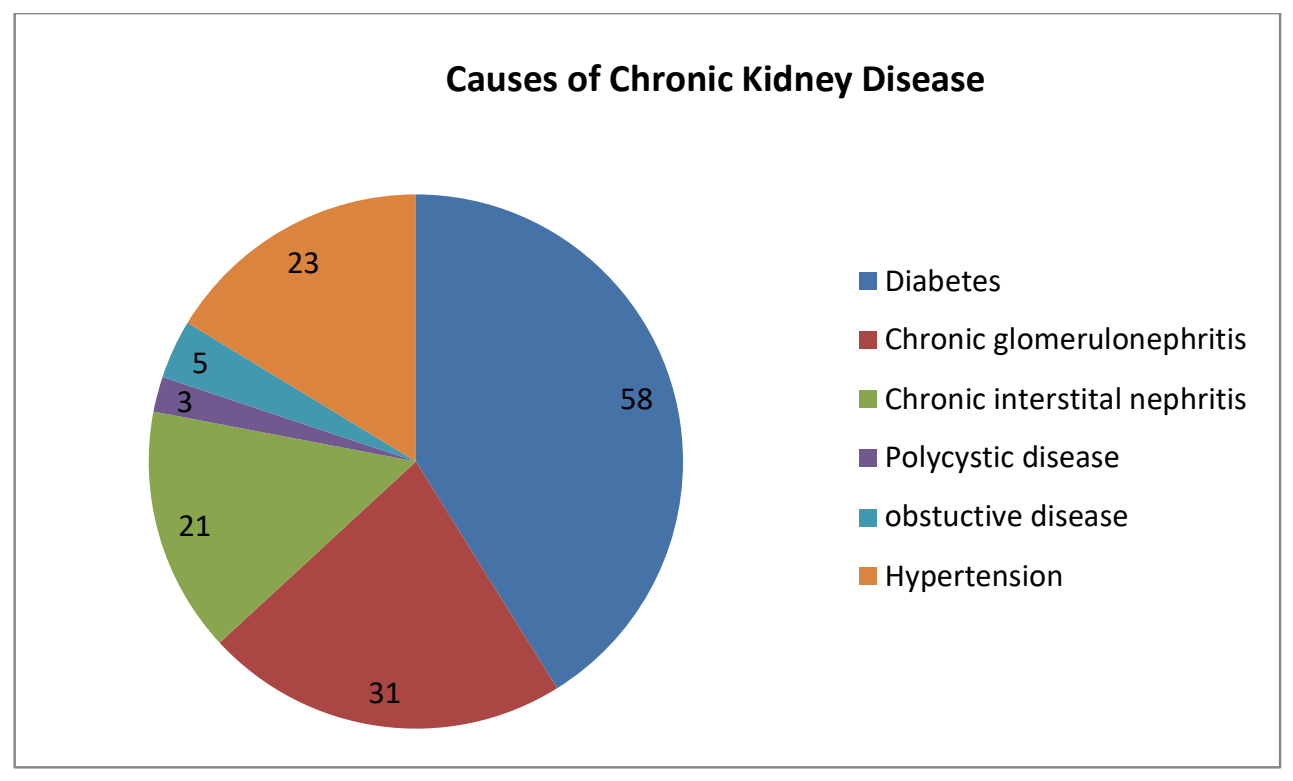

Table 1: showing prevalence of various dermatological conditions

\begin{tabular}{|l|l|l|l|}
\hline S. No. & Skin Condition & No. of patients & Percentage \\
\hline 1 & Xerosis & 104 & 74.8 \\
\hline 2 & Pallor & 93 & 66.4 \\
\hline 3 & Pruritus & 69 & 49.28 \\
\hline 4 & Pigmentary changes & 61 & 43.57 \\
\hline 5 & Nail changes & 57 & 40.71 \\
\hline 6 & Hair changes & 49 & 35 \\
\hline 7 & Cutaneous infection & 46 & 32.8 \\
\hline 8 & Oral mucosa changes & 44 & 29.28 \\
\hline 9 & Purpura & 14 & 10 \\
\hline 10 & Kyrle Disease & 4 & 2.85 \\
\hline
\end{tabular}

All patients had at least one cutaneous manifestation. Thirty four $(24.28 \%)$ patients had two cutaneous manifestations. Twenty one (17.85\%) patients had three or more cutaneous manifestations. Xerosis was most common manifestation. 
Table 2: Severity of Xerosis

\begin{tabular}{|l|l|l|}
\hline Grade & No. Of Patients & Percentage \\
\hline 0 & 36 & 25.71 \\
\hline 1 & 61 & 43.57 \\
\hline 2 & 43 & 30.72 \\
\hline
\end{tabular}

Xerosis was seen in $74.8 \%$ patients. Majority had grade 1 xerosis (table 2)

All patients had at least one cutaneous manifestation. Thirty four (24.28\%) patients had two cutaneous manifestations. Twenty one (17.85\%) patients had three or more cutaneous manifestations. Xerosis was seen in $74.8 \%$ patients. Majority had grade 1 xerosis (table 2). Pallor was observed in 93 patients. Pruritus was seen in sixty nine patients. It was refractory in $28(20 \%)$ patients. Pigmentary changes were common and seen in $43.57 \%$ patients. Diffuse brown pigmentation was observed in forty two patients and yellow pigmentation was seen in nineteen patients. Nail changes were seen in fifty seven patients. Half and half nail was seen in twenty six (18.57\%) patients. Half and Half nail was seen in 16 diabetic patients (16 of 58) and 10 (10 of 82) non diabetic patients. Z score was 2.30 which is significant at $\mathrm{p}<.05$. Beau's line was seen in twelve $(8.57 \%)$ patients. Platynychia was seen in ten $(7.14 \%)$ patients. Absence of lunula was seen in nine $(6.42 \%)$ patients. Onychomycosis was seen in twenty nine patients. 21 patients were diabetic and remaining were non diabetic. $\mathrm{Z}$ test showed score of $4.013(\mathrm{p}<.01)$.

Hair changes were seen in forty nine (35\%) patients. Thirty three patients had sparse hair on scalp. Sixteen patients had lustreless hair. Cutaneous infections were seen in forty six patients. Most common infection was dermatophytosis in twenty eight patients (20\%) Pyoderma was seen in ten patients (7.14\%). Scabies was seen in six (4.28\%) patients. Five patients (3.57\%) had Herpes zoster. Oral mucosa changes were seen in forty six patients. Macroglossia was found in twenty three $(16.42 \%)$ patients. Xerostomia was seen in fourteen (10\%) patients. Ulcerative stomatitis was observed in nine (7.2\%) patients. Purpura was observed in $10 \%$ patients. Kyrle disease or acquired perforating dermatitis was seen in four patients and all had diabetic nephropathy. Two patients showed evidence of metastatic calcification of skin

\section{Discussion}

We observed some kind of renal involvement in all patients [4]. It has been observed by many authors. Xerosis was the most common dermatological manifestation seen in $74.8 \%$ patients.

Uday kumar et al and other authors also found similar results $[2,3,5,6]$. We observed $43.57 \%$ patients with grade 1 and $30.71 \%$ with grade 2 but Uday kumar et al had $71 \%$ with grade 1 . It may be due to more number of diabetic patients in our study. We had 58\% diabetic patients while Uday Kumar et al had 38\%. Diabetic patients have severe xerosis [2]. It may be due to reduction of size of ecrine sweat glands [7]. Pallor was next common manifestation seen in $66.4 \%$ patients. It is due to anaemia seen in majority of patients in CKD. Its incidence is in same range in experience of other study [2]. Deficient erythropoietin production by the failing kidneys and dietary deficiencies of iron, folic acid, and vitamin B12 contribute to anemia [8]. Uremic pruritus is one of the most troublesome symptom in patients with chronic renal failure. It was seen in $49 \%$ patients in our study. Prevalence of pruritus has been described 19 to $90 \%$ by different authors $[2,9,10]$. The etiology of pruritus in CRF is not clear however, it has been associated with advance uremia [11]. Retention of middle molecules such as beta-2 microglobulin, advanced glycosylation end products, and parathyroid hormone also has been implicated in pathogenesis of uremic pruritus [9]. Neuuronal theory is also considered a probable cause for CRF pruritus [12].

Pigmentary changes were seen in $43 \%$ patients in our study. Other authors reported these changes $31-43 \%$ $[2,10]$. Diffuse brown hyperpigmentation is caused by increased levels of $\beta$-melanocyte stimulating hormone due to inadequate excretion through kidney and dialysis [13]. Yellowish tinge is due to excess deposition of two major pigments namely carotenoids and lipochromes in the epidermis and subcutaneous tissue [14]. Nail changes were found in $40.71 \%$ patients in our study. Other authors found these abnormalities in 22 to $60 \%[10,12,15]$. Most common abnormality was half and half nail in $18.57 \%$ patients. It has also been described most common nail change in uremia by others ranges from 16 to $50 \%$ $[5,16,17]$ in comparison to $1.4 \%$ in general population [16]. Half and half nail was more common with diabetic patients. Uday Kumar et al [2] also found same association. Other nail changes were platynychia, Beau's lines and absence of lunula. Similar changes had been described in other studies $[16,17]$. Onychomycosis was 
seen in $20.71 \%$ patients. Uday Kumar et al [2] found incidence of onychomycosis $19 \%$. We found increased incidence of onychomycosis in diabetic patients.

Hair changes were seen in $35 \%$ patients in present study. Sparse hair were found in $23 \%$ patients. It was the commonest hair change. Diffuse hair loss had been described as most common hair change by others $[2,4]$. Dry lustreless hair were found in $12 \%$. Lustreless hair is due to decresed sebum secretion [18]. Cutaneous infections were found in $32.8 \%$ patients. Deshmukh et al also found prevalence of cutaneous infections 34\% [10] while Sultan et al reported cutaneous infection in $40 \%$ patients [16]. Dermatophytosis were the commonest infection in $20 \%$ patients, which is also found in other study [10]. Pyoderma, scabies and Herpes zoster were other cutaneous infections. Similar pattern was found in study by Deshmukh et al [10]. Increased susceptibility to infection in renal failure is due to diminished $\mathrm{T}$ and $\mathrm{B}$ lymphocyte function and count, and reduced natural killer cell activity [19].

Oral mucosal changes were seen in $29 \%$ patients. There are reports of oral mucosal changes from no significant changes [15] to involvement in $90 \%$ patients [20]. Macroglossia (tongue sign of uremia was seen in $14.4 \%$ cases. Xerostomia and ulcerative stomatitis was seen in $10 \%$ and $7 \%$ patients. We observed lesser oral mucosal changes than other Indian study [2] It may be due to geographical variation. Purpura was seen in $10 \%$ cases. Uday Kumar et al also found purpura in $9 \%$ cases [2]. Increased vascular fragility, abnormal platelet function and the use of heparin during dialysis are the main causes of abnormal bleeding in the dialysis patients [21]. Kyrle disease was found in $2.85 \%$ patients. Its prevalence had been described $3 \%$ by Khanna et al [22] and $17 \%$ by Deshmukh et al [10]. Gynecomastia was also seen in $2.85 \%$ cases. Udai Kumar [2] found gynecomastia in $1 \%$ and other study found in $40 \%$ cases [23]. Metastatic calcification was also seen in two patients. It was also seen in $2 \%$ cases in study by Sultan et al [16]. Nephrogenic fibrosing dermopathy (NFD), a recently described disorder of unknown etiology, resembles scleromyxedema in some aspects. We did not see case of NFD in our patients. Other Indian studies also did not find NFD in their patients $[2,22]$.

\section{Conclusion}

Cutaneous manifestations were found in all patients on dialysis. Most common manifestation was xerosis. Other common problems were pruritus, pigmentary changes. Most common nail change was half and half nail. Hair changes were also common. Cutaneous infections were also common problem. Timely recognition and management of these problems may improve quality of life in dialysis patients.

\section{Funding: Nil}

\section{Conflict of interest: Nil}

\section{Permission from IRB: Yes}

\section{References}

1. Pico MR, Lugo-Somolinos A, Sánchez JL, BurgosCalderón R. Cutaneous alterations in patients with chronic renal failure. Int J Dermatol. 1992;31:860-3

2. Udayakumar P, Balasubramanian S, Ramalingam KS, Lakshmi C, Srinivas CR, Mathew AC. Cutaneous manifestations in patients with chronic renal failure on hemodialysis.Indian J Dermatol Venerol Leprol . 2006;72(2):119-25

3. Morton CA, Lafferty M, Hau C, Henderson I, Jones M, Lowe JG. Pruritus and skin hydration during dialysis. Nephron Dial Transplant 1996 Oct;11(10):2031-6

4. Z. Hajheydari and A. Makhlough..Cutaneous and mucosal manifestations in patients on maintenance hemodialysis: a study of 101 patients in Sari, Iran. Iranian Journal of Kidney Diseases 2002:2(2):86-90

5. Tawade N, Gokhale BB. Dermatologic manifestation of chronic renal failure. Indian J Dermatol Venereol Leprol 1996;62:155-6

6. Siddappa K, Nair BK, Ravindra K, Siddesh ER. Skin in systemic disease. In: Valia RG, Valia AR, editors. IADVL Textbook and atlas of dermatology. 2nd ed. Bhalani Publishing House: Mumbai; 2000. pp. 938-84

7. Weisman K. Graham RM. Systemic disease and the skin. In: Champion RH, Burton JL, Burns DA. Breathnach SM, editors. Rook/ Wilkinson/ Ebling Textbook of dermatology. 6th ed. Blackwell Science: Oxford; 1998. pp. 2703-58

8. Graham RM, Cox NH. Systemic disease and the skin. In: Burns DA, Breathnach SM, Cox N, Griffiths CE, editors. Rook's textbook of dermatology. $7^{\text {th }}$ ed. Oxford: Wiley-Blackwell; 2004: pp.59-75

9. Gupta AK, Gupta MA, Cardella CJ, Haberman HF. Cutaneous associations of chronic renal failure and dialysis.Int J Dermatol. 1986;25(8):498-504. 
10. Deshmukh SP, Sharma YK, Dash K, Chaudhari NC, Deo KS. Clinicoepidemiological study of skin manifestations in patients of chronic renal failure on hemodialysis. Indian Dermatol Online J 2013;4:18-21

11. Kato A, Hamada M, Maruyama T, Maruyama Y, Hishida A. Pruritus and hydration state of stratum corneum in hemodialysis patients.Am J Nephrl.2000:20(6):437-42

12. Etter L, Myers SA. Pruritus in systemic disease: Mechanisms and management. Dermatol Clin. 2002;20(3):459-472.

13. Smith AG, Shuster S, Comaish JS, Plummer NA, Thody AJ, Alvarez-Ude F. Plasma immunoreactive $\beta$ Melanocyte stimulating hormone and skin pigmentation in chronic renal failure. Br Med J 1975;1:658-9.

14. Tsaltas TT. Studies of lipochromes in uremic patients and normal controls. II. Isolation and identification of carotenoids and lipochromes and their oxidation products in plasma. Trans Am Soc Artif Intern Organs 1970;16:272-8.

15. Beheshti A, Charkhchian M, Zangivand AA, Sedighi A, Amri G. Dermatological Manifestations Among Patients on Maintenance Hemodialysis. WOUNDS. 2013;25(3):61-67

16. Sultan MM, Mansour HH, Wahby IM, Houdery AS. Cutaneous manifestations in egyptians patients with chronic renal failure on regular hemodialysis. J Egypt Women Dermatol Soc 2010;7:49-55

17. Dyachenko P, Monselise A, Shustak A, Ziv M, Rozenman D. Nail disorders in patients with chronic renal failure and undergoing haemodialysis treatment: A case control study. J Eur Acad Dermatol Venereol 2007;21:340-4.

18. Singh G, Singh SJ, Chakrabarthy N, Siddharaju KS, Prakash JC. Cutaneous manifestations of chronic renal failure. Indian J Dermatol Venereol Leprol 1989;55:1679.

19. Gupta AK, Gupta MA, Cardella CJ, Haberman HF. Cutaneous associations of chronic renal failure and dialysis. Int J Dermatol 1986;25:498-504.

20. Cohen GS. Renal disease. In: Lynch MA, editor. Burket's Oral medicine: Diagnosis and treatment. 9th ed. Philadelphia: Lippincott-Raven; 1997: pp487-509

21. Remuzzi G. Bleeding in renal failure. Lancet 1988;28:1205-8

22. Khanna D, Singhal A, Kalra OP. Comparison of cutaneous manifestations in chronic kidney disease with or without dialysis. Postgrad Med J 2010:86:641-47

23. Lindsay RM, Briggs JD, Luke RG, Boyle IT, Kennedy AC. Gynecomastia in chronic renal failure. Br Med J 1967;4:779-80

\section{How to cite this article?}

Dorchhom K, Kumar A, Bansal N, Pandey AN, Mehta A, Bisth JS, Varma A. Dermatological Manifestations of Patients with Chronic Kidney Disease on Hemodialysis. Int J Med Res Rev 2014;2(6):529-533. doi:10.17511/ijmrr.2014.i06.05 